\section{Cureus}

Received 08/11/2015

Review began 08/14/2015

Review ended 08/18/2015

Published 09/01/2015

\section{(c) Copyright 2015}

Gupta et al. This is an open access article distributed under the terms of the Creative Commons Attribution License CC-BY 3.0., which permits unrestricted use, distribution, and reproduction in any medium, provided the original author and source are credited.

\title{
Gorlin-Goltz Syndrome - A Rare Cause of Recurrent Jaw Pain in a Young Child
}

Monika Gupta ${ }^{1}$, Mahesh K. Mittal ${ }^{1}$, Kanhaiya Agrawal ${ }^{2}$, Amit Kumar Agarwal ${ }^{3}$, Brij B. Thukral $^{2}$

1. Radiology, Safdarjung Hospital 2. The Department of Diagnostic Radiology and Imaging, Safdarjung Hospital 3. Department of Orthopedics, Indraprastha Apollo Hospital, New Delhi

$\square$ Corresponding author: Amit Kumar Agarwal, amitorthopgi@yahoo.co.in Disclosures can be found in Additional Information at the end of the article

\section{Abstract}

Gorlin-Goltz syndrome is an infrequent multisystem disease. At least two major criteria or one major and two minor criteria must be present to make the diagnosis. However, the most important criteria are the presence of basal cell carcinomas, odontogenic keratocysts, palmar and/or plantar pits, and ectopic calcification of falx cerebri. It is necessary to identify the syndrome early due to its predisposition to cancer. An early diagnosis can be made using a multi-disciplinary approach. We report a rare case of an 11-year-old boy with this syndrome with an additional unusual finding of gynaecomastia.

Categories: Pediatrics, Radiology, Orthopedics

Keywords: gorlin syndrome, odontogenic keratocysts, basal cell nevi

\section{Introduction}

Gorlin-Goltz syndrome is a rare multisystem disease with an autosomal dominant inheritance with high level of penetrance and variable expressiveness [1]. It was first described vividly as a distinct entity by Gorlin and Goltz [2]. It is caused by mutation of the tumor suppressor gene PTCH-1 (Patched1) located in the long arm of chromosome 9q22.3-q31 [3]. Studies regarding the cell cycle of human T lymphocytes, human periodontal disease, and human bone augmentation established that more genes belonged to leader- or B-cluster; thus, the resulting number of higher cluster genes was in accordance with the increasing set of genes, which were either candidates to be associated or were found to be robustly associated with osteoporotic disease [4-5]. This syndrome is known by several names, such as nevoid basal cell carcinoma syndrome, Gorlin- syndrome, basal cell nevus syndrome, fifth phacomatosis, multiple basilioma syndrome, hereditary cutaneomandibular polyoncosis, and the most complex one, "Jaw-cyst-basal-cell-nevus, bifid rib syndrome" [6-7]. Nevoid basal cell carcinoma syndrome (NBCCS) and mullerian fusion defects have been found to be associated in the literature [8]. The most important criteria in the diagnosis of this syndrome are the presence of basal cell carcinomas, odontogenic keratocysts, palmar and/or plantar pits, and ectopic calcification of falx cerebri [9-10].

\section{Case Presentation}

An 11-year-old male child with the complaint of recurrent jaw pain of one year's duration presented at our facility for a contrast-enhanced computed tomography (CECT) of the face. Informed patient consent was obtained from his parents for his treatment. 


\section{Cureus}

On general examination, the child had flesh-colored pinpoint papules on the chest and shoulder as well as the incidental finding of gynaecomastia (Figure 1).

FIGURE 1: Clinical images of the child with flesh-colored pinpoint skin lesions, likely basal cell naevi, along with gynecomastia

Suspecting a syndromic association, a chest x-ray was done that showed bifid seventh and eighth ribs anteriorly on each side and splaying of the left eighth and ninth ribs posteriorly as well as the left sixth rib anteriorly. 


\section{Cureus}

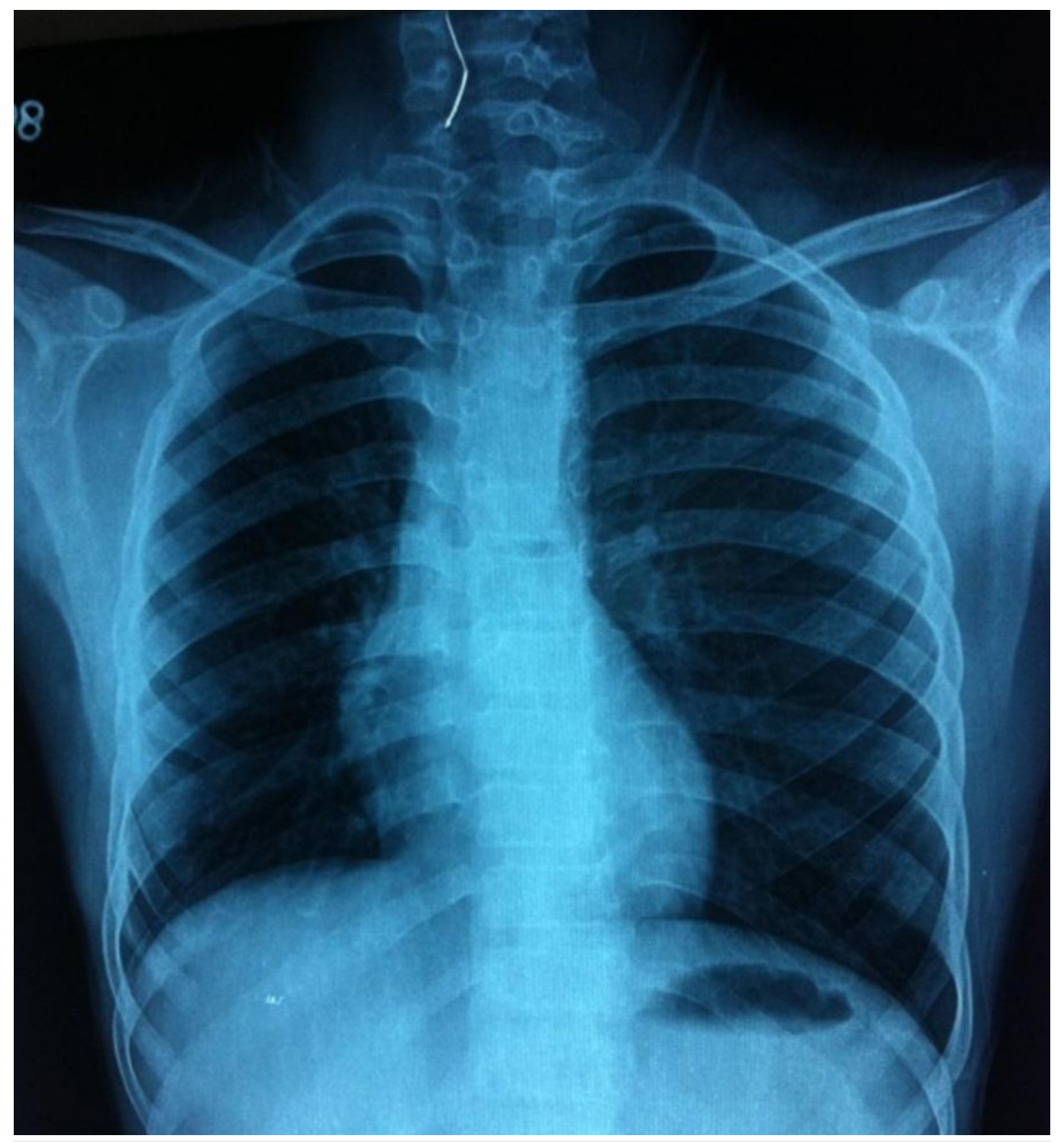

FIGURE 2: Chest X-ray (PA) showing bifid 7th and 8th ribs anteriorly on each side, splaying of left 8th, 9th ribs posteriorly and 6th rib anteriorly

An orthopantomogram (OPG) was also done which showed multiple lucent areas in the mandible with a unerupted tooth. 


\section{Cureus}

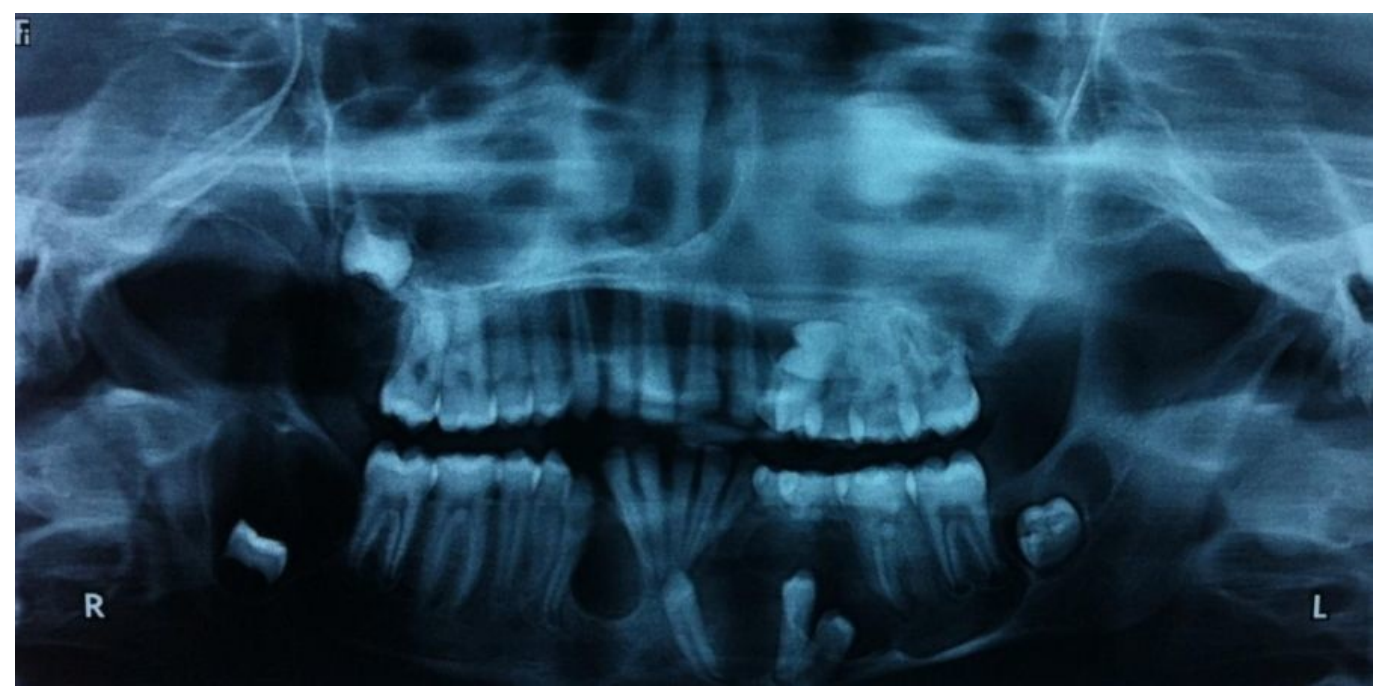

FIGURE 3: An orthopantogram (OPG) showing multiple lucent areas with unerupted teeth

No significant family history/history were present. No previous imaging was available. A CECT face was done which revealed multiple expansile non-enhancing cystic areas with cortical thinning involving the mandible (Figure 4). Some of these lesions were associated with an unerupted tooth (Figure 5).

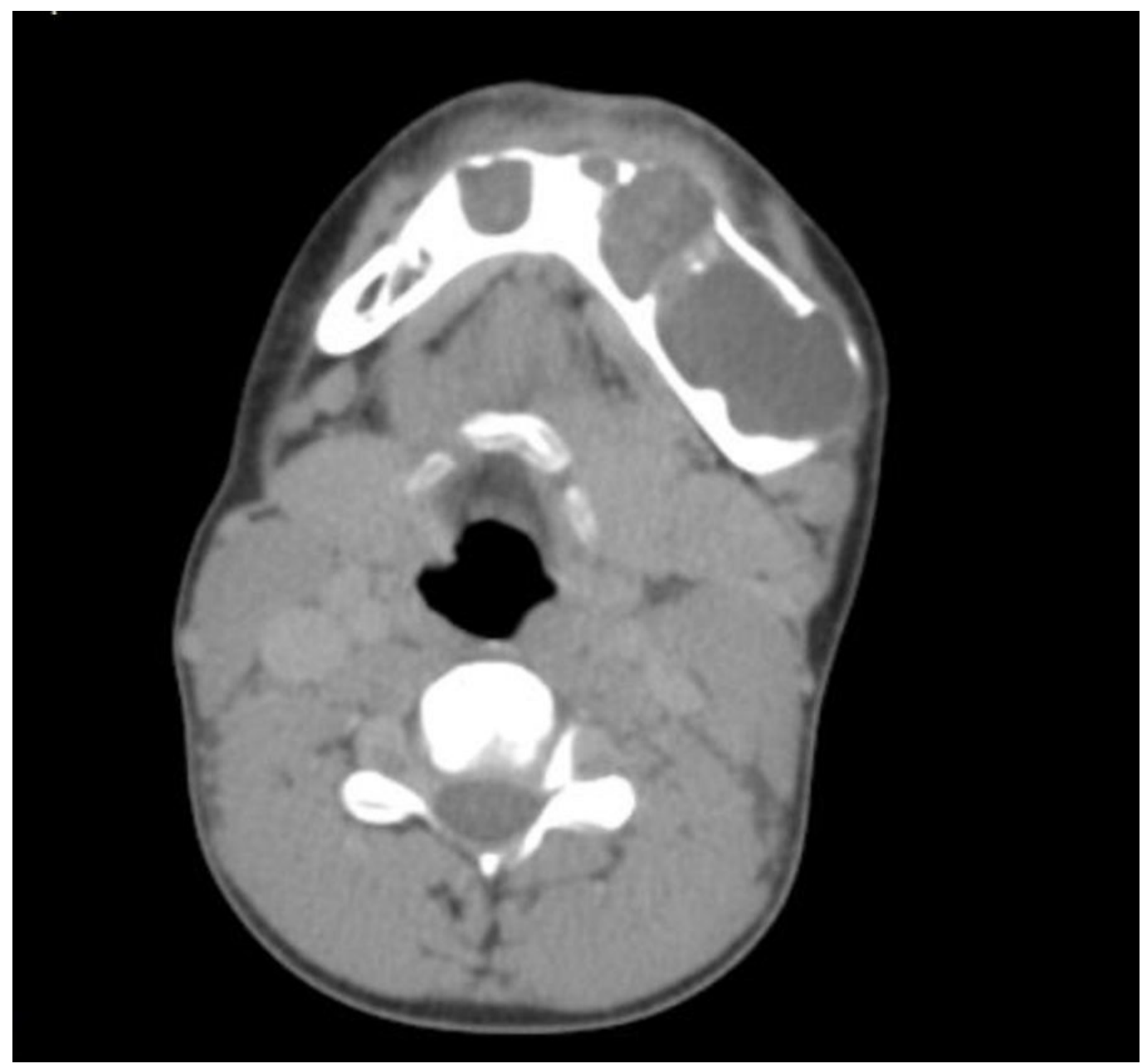




\section{Cureus}

FIGURE 4: CT scan of the face shows multiple cystic nonenhancing lesions with cortical thinning

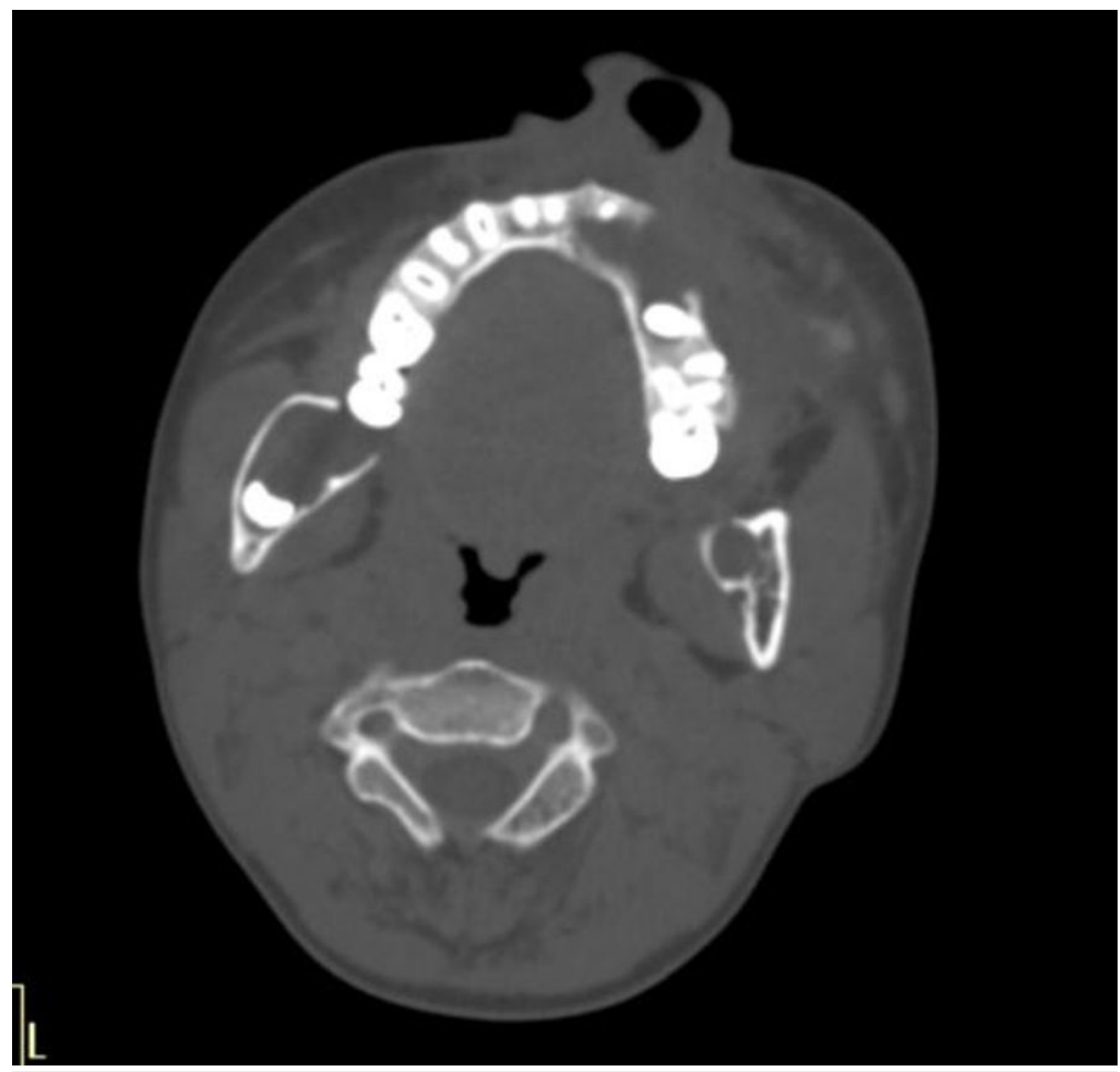

FIGURE 5: CT scan of the face shows multiple cystic nonenhancing lesions with unerupted teeth and cortical thinning

Few calcific foci in the falx cerebri and tentorium were seen in the topmost images of the study (Figure 6). 


\section{Cureus}

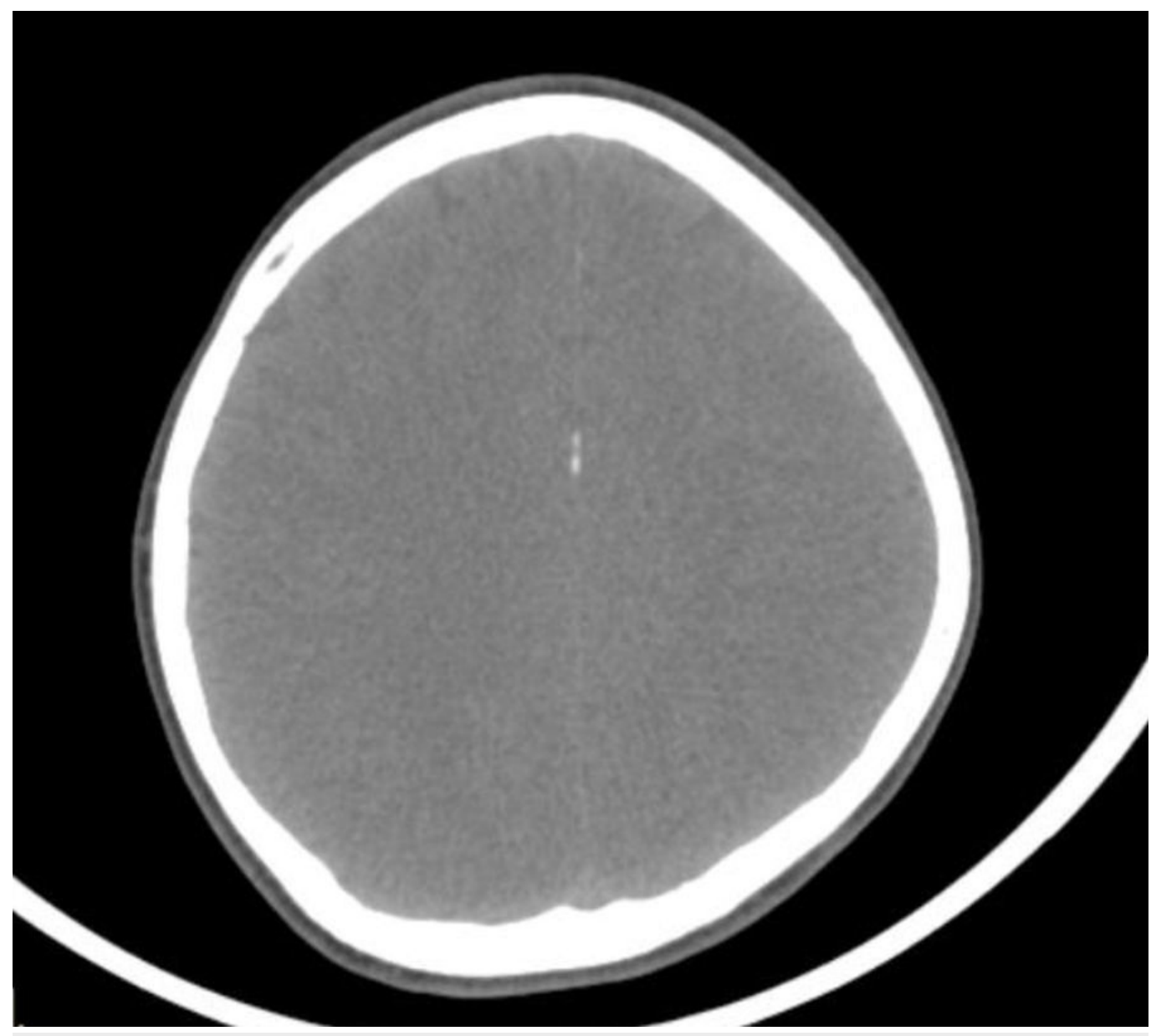

FIGURE 6: CT scan showing calcification of falx cerebri and tentorium

Based on clinical history and radiographic findings, a provisional diagnosis of Gorlin-Goltz syndrome was made. The patient then underwent excisional biopsy from the jaw cysts

(Figure 7). The histopathological report was suggestive of multiple odontogenic keratocysts (OKC) (Figure 8). 


\section{Cureus}

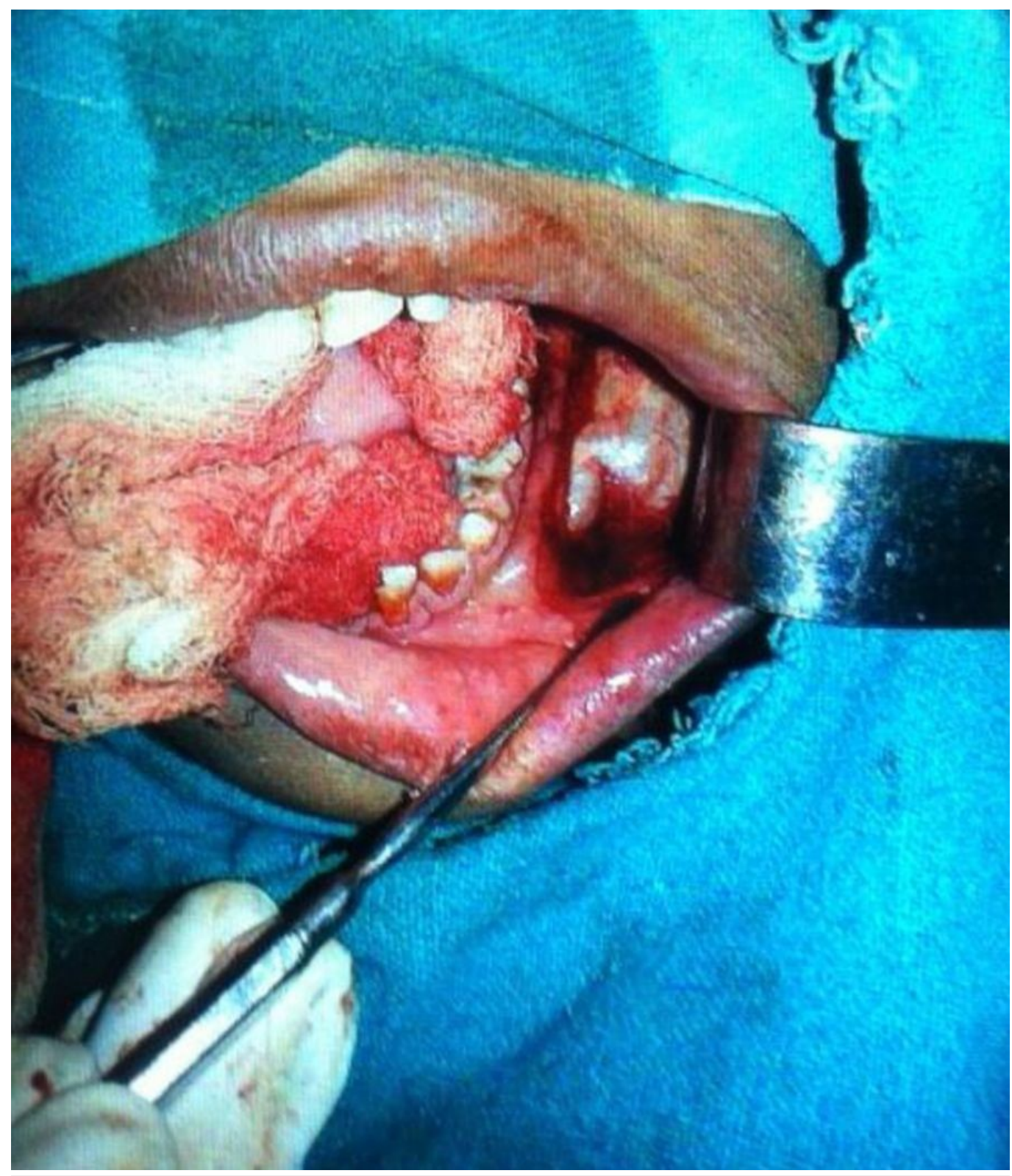

FIGURE 7: Intraoperative image showing excision of jaw cyst 


\section{Cureus}

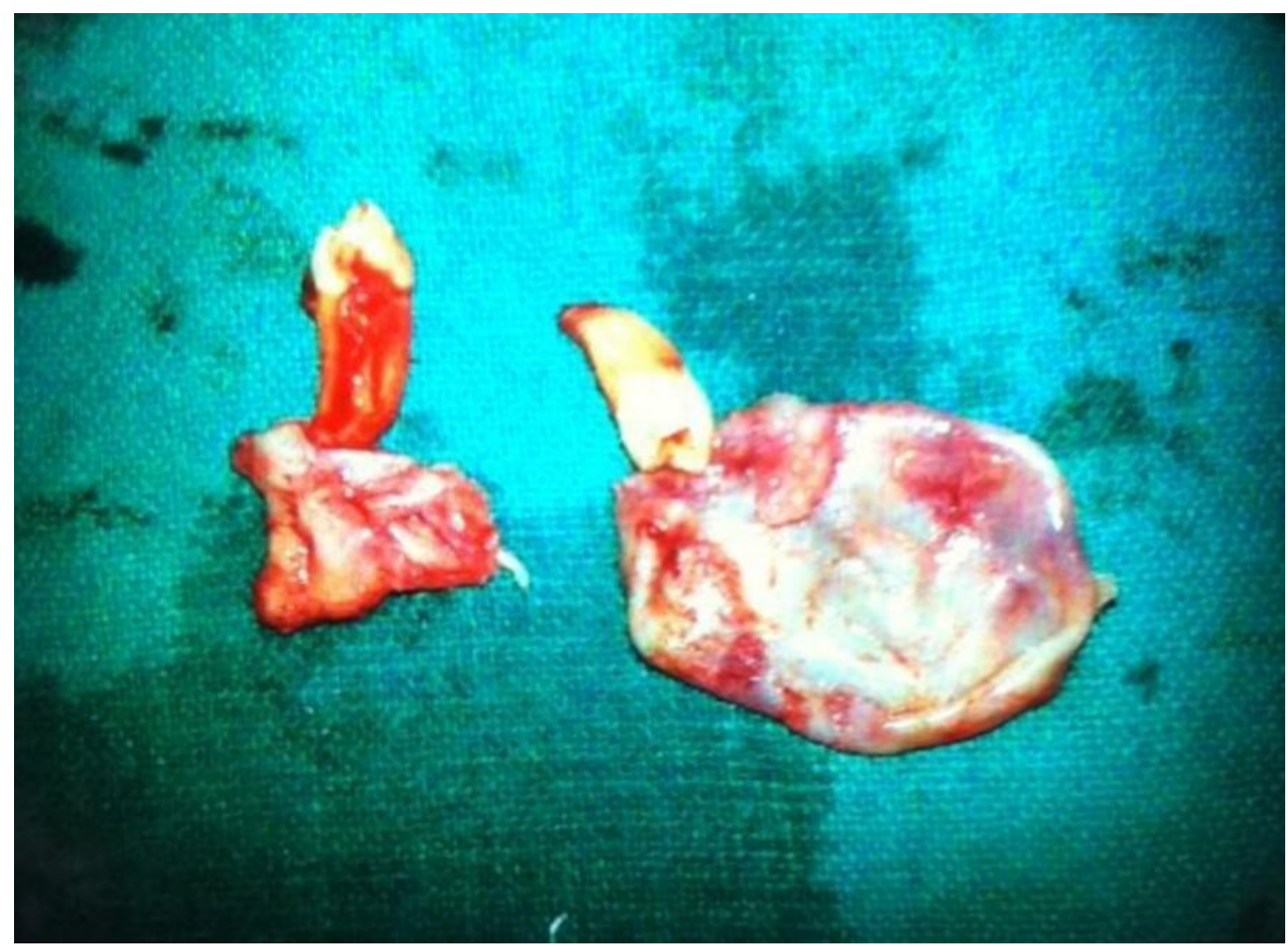

FIGURE 8: Resected specimen of the jaw cysts. Note two cysts with associated teeth. Histopathology shows odontogenic keratocysts (OKC)

\section{Discussion}

Gorlin-Goltz syndrome is a rare inherited multisystem syndrome manifested by multiple defects. The classic triad described consists of multiple basal cell carcinomas of the skin, odontogenic keratocysts of the jaw, and bifid ribs. Kimonis, et al. proposed the diagnostic criteria when two major or one major and two minor criteria are required to make the diagnosis [11].

\section{Major Criteria:}

- Two or more basal cell carcinomas or one in persons younger than 20 years.

- Odontogenic keratocysts of the jaw.

- Three or more palmar or plantar pits.

- Bilamellar calcification of the falx cerebri.

- Bifid, fused, or markedly splayed ribs.

- First-degree relative with Gorlin syndrome.

Minor Criteria: 
- Macrocephaly.

- Congenital malformations (cleft lip or palate, frontal bossing, coarse face, hypertelorism).

- Skeletal abnormalities (Sprengel deformity, marked pectus deformity, or syndactyly of the digits).

- Radiologic abnormalities (bridging of the sella turcica, vertebral anomalies like hemivertebrae, fusion or elongation of the vertebral bodies, modelling defects of the hands and feet, or flame-shaped lucencies of the hands or feet).

- Ovarian /cardiac fibroma.

- Medulloblastoma.

This case fulfills more than two major criteria of Gorlin-Goltz syndrome: multiple odontogenic keratocysts (OKC), multiple basal cell naevi, bifid splayed ribs, and calcification of the falx cerebri and tentorium cerebri. Multiple skeletal anomalies are seen, including kyphoscoliosis, blocked vertebrae, hemivertebrae, spina bifida occulta, short fourth metacarpals, pectus carinatum or pectus excavatum, and Sprengel's deformity. The rib anomalies include splaying, synostosis, and cervical ribs. The odontogenic keratocysts are one of the most common (seen in more than $90 \%$ of the cases) and early manifestations (usually in the second decade) of this syndrome. There is a risk of the development of an ameloblastoma or squamous cell carcinoma in these cysts. In the CNS manifestations, bilamellar calcification of falx cerebri is frequently reported to be associated with this syndrome. Few CNS neoplasms, such as medulloblastoma, meningioma, astrocytoma, and craniopharyngioma, have also been reported to be associated. Ovarian calcification, ovarian cysts, and ovarian and cardiac fibromas have also been described.

The significance of recognizing Gorlin-Goltz syndrome is due to its predisposition to cancer at an early age. As described earlier, basal cell naevi occur at a younger age group. However, exposure to UV rays predisposes one to basal cell carcinoma at a young age. The diagnosis can be made by family history, clinical examination, and radiological investigations like plain radiographs, CT scan, MRI brain (for CNS neoplasms), and pelvic ultrasonography in females to look for ovarian fibromas. An incidental finding of gynecomastia was also seen in our case. However, it has yet to be associated more frequently to be documented as a consistent feature of the syndrome. The diagnosis usually is confirmed by gene mutation analysis. Treatment options available for the keratocysts include surgical enucleation with curettage, enucleation with a peripheral osteotomy, or osseous resection en bloc.

\section{Conclusions}

The diagnosis and management of Gorlin-Goltz syndrome requires a multidisciplinary approach. The diagnosis is made by thorough history taking, clinical examination, and various radiological investigations. Findings may include multiple basal cell carcinomas, odontogenic keratocysts, palmar and plantar pits, various skeletal and rib abnormalities, and CNS manifestations. The patient usually presents with multiple recurrent jaw swellings. It is necessary to identify the syndrome due to its predisposition to cancer at an early age.

\section{Additional Information}

\section{Disclosures}

Human subjects: Consent was obtained by all participants in this study. Conflicts of interest: In compliance with the ICMJE uniform disclosure form, all authors declare the following: 
Payment/services info: All authors have declared that no financial support was received from any organization for the submitted work. Financial relationships: All authors have declared that they have no financial relationships at present or within the previous three years with any organizations that might have an interest in the submitted work. Other relationships: All authors have declared that there are no other relationships or activities that could appear to have influenced the submitted work.

\section{References}

1. Agrawal A, Murari A, Vutukuri S, Singh A: Gorlin-Goltz Syndrome: Case report of a rare hereditary disorder. Case Rep Dent. 2012, 2012:475439. 10.1155/2012/475439

2. Gorlin RJ, Goltz RW: Multiple nevoid basal-cell epithelioma, jaw cysts and bifid rib. A syndrome. NEJM. 1960, 262:908-12. 10.1056/NEJM196005052621803

3. Matsuzawa N, Nagao T, Shimozato K, Niikawa N, Yoshiura KI: Patched homologue 1 mutations in four Japanese families with basal cell nevus syndrome. J Clin Pathol. 2006, 59:1084-86. 10.1136/jcp.2005.029439

4. Toti P, Sbordone C, Martuscelli R, Califano L, Ramaglia L, Sbordone L: Gene clustering analysis in human osteoporosis disease and modifications of the jawbone. Arch Oral Biol. 2013, 58:912-29. 10.1016/j.archoralbio.2013.02.013

5. Sbordone L, Sbordone C, Filice N, Menchini-Fabris G, Baldoni M, Toti P: Gene clustering analysis in human osseous remodeling. J Periodontol. 2009, 80:1998-2009.

10.1902/jop.2009.090290

6. Ortega García de Amezaga A, García Arregui O, Zepeda Nuño S, Acha Sagredo A, Aguirre Urizar JM: Gorlin-Goltz syndrome: clinicopathologic aspects. Med Oral Patol Oral Cir Bucal. 2008, 13:E338-43.

7. Mohan RPS, Vemanna NS, Narayanappa SM, Verma S, Gupta N, Sidhu VK: Gorlin-Goltz syndrome: A clinic radiological illustrative case report. Indian J Dent. 2013, 4:165-69. 10.1016/j.ijd.2013.05.007

8. Ramaglia L, Morgese F, Pighetti M, Saviano R: Odontogenic keratocyst and uterus bicornis in nevoid basal cell carcinoma syndrome: case report and literature review. Oral Surg Oral Med Oral Pathol Oral Radiol Endod. 2006, 102:217-19. 10.1016/j.tripleo.2005.08.009

9. Jones EA, Sajid MI, Shenton A, Evans DG: Basal cell carcinomas in Gorlin syndrome: a review of 202 patients. J Skin Cancer. 2011, 2011:217378. 10.1155/2011/217378

10. Kantarci M, Ertas U, Alper F, Sutbeyaz Y, Karasen RM, Onbas O: Gorlin's syndrome with a thin corpus callosum and a third ventricular cyst. Neuroradiology. 2003, 45:390-92.

10.1007/s00234-003-0988-y

11. Kimonis VE, Goldstein AM, Pastakia B, Yang ML, Kase R, DiGiovanna JJ, Bale AE, Bale SJ: Clinical manifestations in 105 persons with nevoid basal cell carcinoma syndrome. Am J Med Genet. 1997, 69:299-308. 10.1002/(SICI)1096-8628(19970331)69:3<299::AID-

AJMG16>3.0.CO;2-M 